\title{
Posteroinferior giant true aneurysm of the left ventricle presenting as pseudoaneurysm
}

\author{
Michael Toumbouras, MD, K. Rammos, MD, and P. Spanos, MD, Thessaloniki, Greece
}

$\mathrm{P}$

osteroinferior aneurysms of the left ventricle are rare, and in comparison with anterior wall aneurysms, a higher percentage of reported inferior wall aneurysms were classified as false. ${ }^{1,2}$ We report the case of a patient who had the clinical picture of congestive heart failure and mitral regurgitation.

\section{Clinical Summary}

A 69-year-old man was admitted with a 2-month history of advanced congestive heart failure and mitral regurgitation. Thirty months earlier, the patient underwent a 3-vessel revascularization of the main coronary arteries. The ventriculogram at that time
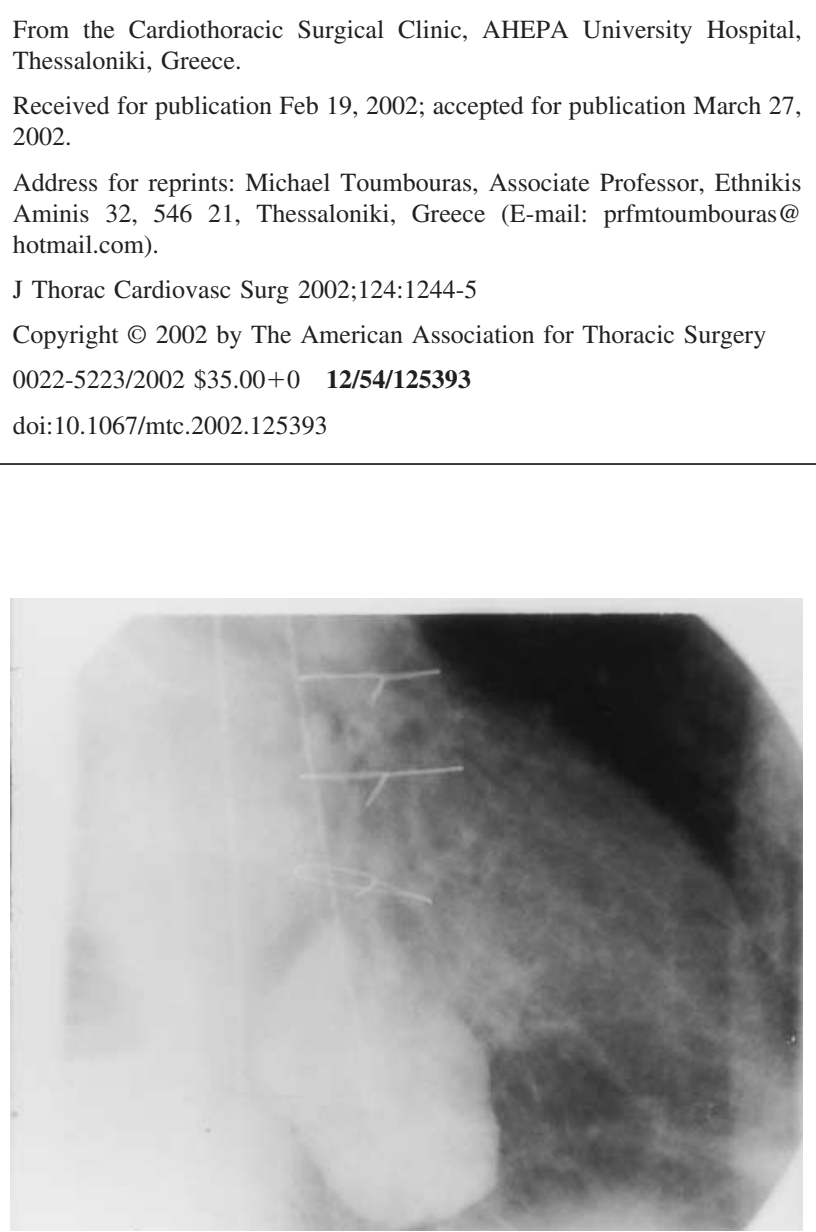

Figure 1. Ventriculogram in the right anterior oblique projection 30 months after a coronary artery bypass grafting operation. Shown is a giant aneurysm $(3.0 \times 5.5 \times 11.5 \mathrm{~cm}$ in size $)$ of the posterior wall of the left ventricle with a narrow neck relative to the diameter, suggesting a typical false aneurysm. showed a postinfarction abnormal diastolic contour with dyskinetic segments in systole of the posterior wall of the left ventricle. On repeat cardiac catheterization, the 3 grafts to the main coronary arteries were patent; ventriculography in the right anterior oblique projection demonstrated a giant aneurysm $(3.0 \times 5.5 \times 11.5 \mathrm{~cm})$ arising from the inferior wall of the left ventricle with a narrow neck relative to the diameter, suggesting a typical false aneurysm (Figure 1). The aneurysm was associated with mitral valve regurgitation.

The aneurysm was resected (Dor procedure ${ }^{3}$ ), and the mitral valve was reconstructed (Figure 2). Intraoperative and pathologic examination revealed that the aneurysmal wall was only 1.2 to 2 $\mathrm{mm}$ thick, but it was a true aneurysm that contained coronary artery and myocardial cells in its wall.

The patient did well. He is now in functional class II 3 months after the operation (Figure 3).

\section{Comment}

The natural history of this aneurysm, with its rapid enlargement and its pseudoaneurysm-like shape in left ventriculography, is

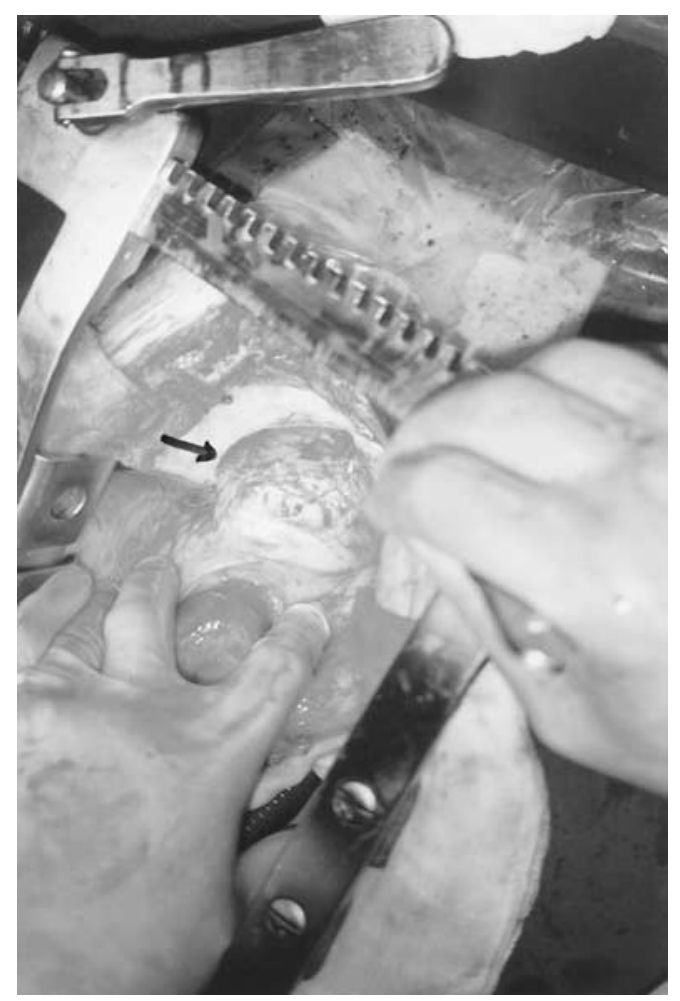

Figure 2. Intraoperative view of the aneurysm. 
rarely seen. The differential diagnosis between true and false aneurysms can be difficult, and pathologic examination is necessary to establish the diagnosis. ${ }^{4}$ Because of the associated propensity toward rupture of such lesions, an aggressive surgical approach is recommended.

\section{References}

1. Ito T, Migata Y, Domiya T, et al. A case of post-infarction true left ventricular aneurysm, which showed pseudoaneurysm-like shape in left ventriculography. Kyobu Geka. 1992;45:541-3.

2. Bendiktsson R, Eyjolfsson O, Thorgeirsso G. Natural history of chronic left ventricular aneurysm; a population based cohort study. J Clin Epidemiol. 1991;44:1131-9.

3. Dor V, Saab M, Coste P, et al. Left ventricular aneurysm: a new surgical approach. Thorac Cardiovasc Surg. 1989;37:11-9.

4. Lascault G, Reeves F, Drobinski G. Evidence of the inaccuracy of standard echocardiographic and angiographic criteria used for the recognition of the true and "false" left ventricular inferior aneurysms. Br Heart J. 1988;60:125-7.

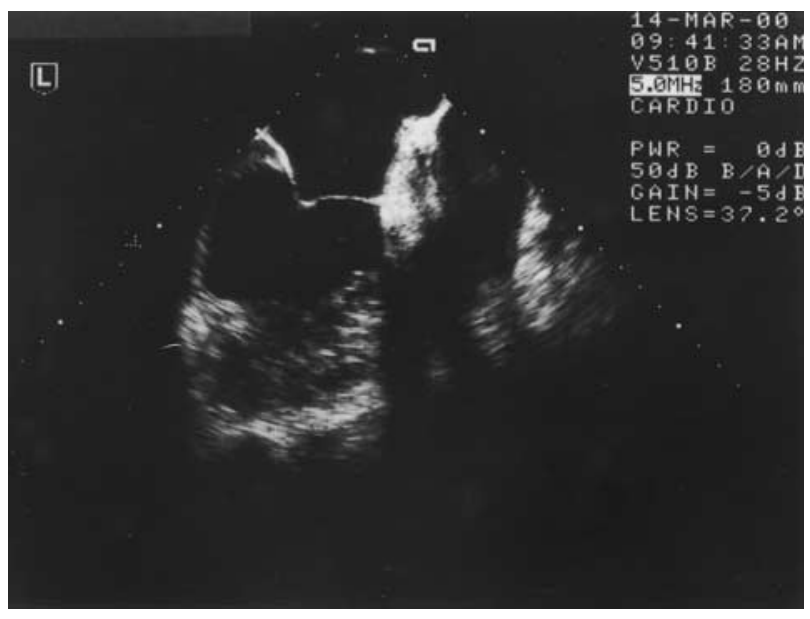

Figure 3. Transesophageal echocardiogram at a $90^{\circ}$ plane 3 months after aneurysmectomy and the Dor procedure and mitral valve reconstruction. 